\title{
In vivo evaluation of nanostructured lipid carrier systems (NLCs) in mice bearing prostate cancer tumours
}

\author{
Mushfiq Akanda $^{1,2} \cdot$ Giulia Getti $^{1} \cdot$ Dennis Douroumis ${ }^{1,2}$ (1)
}

Accepted: 10 November 2021

(c) The Author(s) 2021

\begin{abstract}
Nanostructure lipid carriers (NLCs) were developed for the delivery of curmumin (CRN), a potent anticancer agent with low bioavailability, for the treatment of prostate cancer. NLCs prepared using high pressure homogenization (HPH) with around $150 \mathrm{~nm}$ particle size, $-40 \mathrm{~V} \zeta$-potential and excellent long-term stability. Cellular uptake of CRN-SLN showed nanoparticle localization in the cytoplasm around the nucleus. CRN-NLCs were assessed using flow cytometry and found to cause early and late apoptotic events at $100 \mu \mathrm{g} / \mathrm{ml} \mathrm{CRN} \mathrm{concentrations.} \mathrm{CRN-NLC} \mathrm{nanoparticles} \mathrm{were} \mathrm{administrated} \mathrm{to}$ nude mice with LNCaP prostate cancer xenografts and demonstrated substantial tumour volume suppression (40\%) with no weight loss compared to pure CRN (ethanolic solution). Overall, NLCs were proved a suitable carrier for passive drug delivery and cancer treatment.
\end{abstract}

Keywords Nanostructured lipid carriers · Curcumin · Prostate cancer · In vivo · Apoptosis · Cellular uptake

\section{Introduction}

Nanostructured lipid carriers (NLCs) are versatile drug delivery systems that have been employed for the delivery of drug substances with enhanced clinical efficacy. Their wide applicability lies on the unique features they present such as increased drug encapsulations, long term physical and chemical stability of the encapsulated drug, surface functionalization and site-specific targeting [1, 2]. Furthermore, they can be easily produced using high pressure homogenization (HPH) under aseptic conditions while scale-up can be performed in a batch or continuous mode reaching a capacity of $100-150 \mathrm{~kg} / \mathrm{h}$.

NLCs were introduced by Rainer H. Müller (Berlin/ Germany) and Maria Rosa Gasco (Turin/Italy) comprising solid and liquid lipid blends which result in imperfection of the lipid matrix due to large distances between the fatty acid chains [3]. Numerous studies have demonstrated why NLCs are considered to be a superior drug delivery system

Dennis Douroumis

d.douroumis@gre.ac.uk

1 Medway School of Science, Faculty of Engineering and Science, University of Greenwich, Kent ME4 4TB, UK

2 Centre for Innovation \& Process Engineering Research, Chatam Maritime, Kent ME4 4TB, UK compared to other nano lipidic delivery systems. Alam et al. developed isradipine-loaded NLCs for the management of hypertension and myocardial infraction [4]. Clinical studies showed that NLC treatment prevents significantly the antioxidant status and ultrastructural changes of the heart due to the isradipine increased bioavailability. Thermoreversible NLCs were used to form in situ implants and achieve sustained release of estradiol valearate [5]. The developed NLC formulations showed an increase of 16.8fold in AUC and 40-fold of Cmax when compared to a commercial suspension.

NLCs have been also used as carriers for transdermal delivery due to the increase of solubility of water insoluble drug substances [4, 6-10]. A dermatokinetic assessment involved the administration of luliconazole-loaded NLCs with ultra-small particle size $(<100 \mathrm{~nm})$ for antifungal activity [6]. Nanoparticles were loaded in a topical gel, and clinical results showed twofold increase of Cmax and threefold for the AUC compared to a marketed cream. Recently, a novel NLC formulation was designed for co-delivery of tacrolimus and siRNA for the treatment of psoriasis [11]. The in vivo studies confirmed the superiority of NLCs with significant reduction of the cytokine TNF- $\alpha$ expression and demonstrated the synergistic effect of tacrolimus and TNF- $\alpha$ siRNA with a sevenfold increase. In other studies, NLCs have been reported for brain targeting to treat Alzheimer's 
disease [12] or for lymph targeting and the delivery of antiHIV agents [13].

However, NCLs have been extensively used for cancer treatment combined with chemotherapy to overcome challenges associated with tumours $[14,15]$. In a recent study, surface-engineered NLCs were developed for combined chemotherapy through the delivery of docetaxel and curcumin by conjugating folic acid. The dual drug delivery offers several advantages such as dose reduction, overcoming of multi-drug resistance and can result in synergistic effects. The in vivo studies in murine lung carcinoma showed enhanced docetaxel bioavailability and tumour regression compared to Taxotrene ${ }^{\circledR}$. NLCs loaded with Ibrutinib were developed using a Quality by Design approach for the treatment of chronic lymphocytic leukaemia. Nanoparticles of $106 \mathrm{~nm}$ and encapsulation efficiency of $70 \%$ demonstrated improved pharmacokinetic results with increased Cmax (2.9-fold), AUC (5.3fold) and mean residence time (1.8-fold) in comparison to the free Ibrutinib. The clinical efficacy of NLCs was also better when lymphatic uptake was investigated by blocking chylomicron flow blocking by incorporating cycloheximide.

In the current study, we developed curcumin-loaded NLCs for the treatment of prostate cancer. The nanoparticles presented excellent physical stability under storage and showed a dose-dependent effect on cellular uptake and cytotoxicity. In vivo animal studies demonstrated significant tumour regression when compared to bulk curcumin.

\section{Materials}

Tristearin, oleic acid, stearic acid, Tween 80 and curcumin were purchased from Merck (Gillingham, UK). Lutrol 407 was kindly provided by BASF (UK). All other solvents such as acetonitrile (ACN), ethanol (EtOH) and chemicals were of analytical grades. LNCaP cell lines were obtained from American Type Culture Collection (Virginia, USA). Thiazolyl blue tetrazolium bromide (MTT), Dulbecco's modified Eagle's medium (DMEM), Penicillin streptomycin, L-glutamin, heat inactivated fetal bovin serum (FBS) and trypsin were also acquired from Merck (UK). The Annexin V Apoptosis Detection Kit I was purchased from BD Biosciences.

\section{Methods}

\section{Fabrication of NLC nanoparticles}

The NLCs were prepared by means of a pre-emulsification step followed by high-pressure homogenization (HPH) with the lipid phase, comprising a blend of oleic and stearic acid. Briefly, NLC-containing suitable quantities of both solid and oily lipids, surfactants (Lutrol 407, Tween 80 with or without curcumin (CRN) are used, as shown in Table 1. The volume of the aqueous phase was kept at $50 \mathrm{ml}$. The NLCs comprised blank or CRN loaded which were primarily heated over the lipid's melting point. For the CRN-loaded NLCs, the drug was dissolved in $3 \mathrm{ml}$ of ethanol and added in the molten lipidic blend and subsequently dispersed in the surfactant solution $\left(80^{\circ} \mathrm{C}\right)$ and processed using an UltraTurrax T25 homogenizer (IKA ${ }^{\circledR}$ $\mathrm{GmbH}$, Germany) to obtain the pre-emulsion. The crude dispersion obtained from the pre-emulsification step was placed in a Micro DeBee (South Easton, MA, USA) HPH and processed continuously for $7 \mathrm{~min}$ at $70{ }^{\circ} \mathrm{C}$ and 15,000 PSI. The final NLC dispersions were allowed to cool down at ambient temperature and the lipid to crystallize forming a solid matrix of lipid nanoparticles.

\section{Particle size and ל-potential analysis}

The obtained NLCs were evaluated for their particle size and $\zeta$-potential using dynamic light scattering with the Zetasizer Nano-ZS (Malvern, UK). The nanoparticles were diluted (2-3 droplets) in purified water (dispersant), and each sample was measured in triplicate.

\section{Evaluation of drug loading and encapsulation efficiency}

The encapsulated CRN in the NLC was estimated through a UV-vis spectrophotometer at $\lambda$ max of $425 \mathrm{~nm}$ by constructing a calibration curve $\left(R^{2} 0.999\right)$ of drug concentrations varying from 1 to $30 \mu \mathrm{g} / \mathrm{ml}$ (Douroumis 2011). Briefly, $1 \mathrm{ml}(\times 3)$ of nanoparticles were centrifuged for $30 \mathrm{~min}$ at $14,000 \mathrm{rpm}$ and $25^{\circ} \mathrm{C}$. The collected pellets of $\mathrm{CRN}$ were dissolved in $\mathrm{ACN}$ to measure the $\mathrm{CRN}$ absorbance followed by suitable dilutions. The determined CRN amounts provided the accurate drug loading (DL) and the encapsulation efficiency (EE) using Eqs. 1 and 2:
Table 1 Formulations of blank and drug-loaded NLCs

\begin{tabular}{lllllll}
\hline Formulations & $\begin{array}{l}\text { Tristearin } \\
(\mathbf{m g})\end{array}$ & $\begin{array}{l}\text { Oleic acid } \\
(\mathbf{m g})\end{array}$ & $\begin{array}{l}\text { Lutrol 407 } \\
(\mathbf{m g})\end{array}$ & Tween 80 (mg) & CRN (mg) & Water (ml) \\
\hline BL-NLCs & 400 & 250 & 150 & 100 & 90 & 50 \\
CRN-NLCs & 400 & 250 & 150 & 100 & 90 & 50 \\
\hline
\end{tabular}




$$
\begin{aligned}
& D L=\frac{\text { Amount of CRN in NLCs }}{\text { Amount of NLCs }} \times 100 \\
& E E=\frac{\text { Drug loading }}{\text { Theoretical drug loading }} \times 100
\end{aligned}
$$

\section{CRN release from NLCs}

The CRN release from the nanoparticles was estimated by transferring $1 \mathrm{ml}(\times 3)$ of NLCs into dialysis bags (cellulose grade with 10,000 molecular weight cut-off), and placed in beakers comprising $0.51 \mathrm{ddH}_{2} \mathrm{O}$ and $\mathrm{EtOH}$ with 50:50, v/v ratio at $37^{\circ} \mathrm{C}$, similarly to Yang et al. [16]. All beakers were introduced in a water bath shaker (Thermo Scientific Precision TSGP15D) and at different time intervals, the dissolution media were collected and exchanged with additional $0.5 \mathrm{~L}$ of the same media. The CRN amounts were estimated spectrophotometrically as before $(\lambda \max 425 \mathrm{~nm})$.

\section{Cytotoxicity studies}

LNCaP cancer cells were cultured using Dulbecco's modified Eagle's medium with the addition of serum (10.0\%), L-glutamine $(1.0 \%)$ and penicillin streptomycin $(1.0 \%)$ at $37{ }^{\circ} \mathrm{C}$ while $5 \% \mathrm{CO}_{2}$ was supplied. The DMEM medium was replaced after 3 days.

The cytotoxicity of bulk CRN and CRN-NLCs was estimated using MTT assay with LNCaPs seeded in 24-well plates with cell densities of $1 \times 10^{6}$ cells/well after $24 \mathrm{~h}$ incubation. Appropriate amounts of MTT solution (100 $\mu$ l, $5 \mathrm{mg} / \mathrm{ml}$ ) were added in each plate and incubated for another $2 \mathrm{~h}$ at $37^{\circ} \mathrm{C}$. Subsequently, the medium was rejected, and acidified isopropanol $(200 \mu \mathrm{l})$ was added to solubilise the formazan crystals, which were placed into 96-well plates for absorbance measurements $(492 \mathrm{~nm})$ with a microplate reader. CRN amounts varied at concentrations from 10 to $100 \mu \mathrm{g} / \mathrm{ml}$. Similarly, BL-NLC and CRN-NLC dispersions were incubated at $0.10,0.20,0.40,0.60$ and $0.90 \mathrm{mg} / \mathrm{ml}$.

\section{Cellular uptake}

The cellular uptake of NLC dispersions was determined after seeding $20 \times 10^{3}$ cells/well on 24 -well plates. The CRN-NLC samples were incubated with LNCaP cell for $24 \mathrm{~h}$ at different concentrations. After $24 \mathrm{~h}$, the cell medium was removed and rinsed with a phosphate buffer solution (3 times). The cells were left in the dark for $15 \mathrm{~min}$ after the addition of $1 \mathrm{ml}$ paraformaldehyde (4\%) to fix them on the cover slips and subsequently mounted on glass slides with a vectashield medium enclosing DAPI. The uptake of CRC-NLCs was determined using the CRC fluorescence intensity which excites at $425 \mathrm{~nm}$ and emits at $530 \mathrm{~nm}$ [17]. Fluorescent images were collected with a Nikon ECLIPSE 90i microscope coupled to a Nikon (DS-Qi1Nc) digital camera using the NIS-Elements Advanced Research software. For the imaging studies, an oil immersion CFI Plan Apochromat VC $60 \times \mathrm{N} 2$ was used.

\section{Flow cytometry analysis}

Due to CRN intrinsic green fluorescence, the cellular uptake was quantitatively estimated by Flow cytometry. As previously, $20 \times 10^{3}$ cells/well were seeded on cover slips in 24-well plates, while the cells were incubated with CRN (ethanolic solution) and NLC dispersions $(10 \mu \mathrm{g} / \mathrm{ml})$ for $24 \mathrm{~h}$. After discarding the medium and washing three times with PBS, the cells were separated from the well plates by adding EDTA. At the end of the trypsinization process cells were again rinsed three times and dispersed in $500 \mu \mathrm{L}$ of PBS for analysis.

\section{Studies of in vitro apoptosis}

Briefly, LNCaP cells were seeded in 24-well plates and incubated for $48 \mathrm{~h}$ with cell densities of $1 \times 10^{6}$ cells/well. Subsequently, the cells were centrifuged, collected, rinsed three times with PBS and re-suspended in $1 \times$ binding buffer (500 mL), 7-amino-actinomycin (7AAD, $5 \mu \mathrm{l}$ ), PE Annexin V $(5 \mu \mathrm{l})$ and incubated for $10 \mathrm{~min}$ under dark. The prepared samples were examined for the 7AAD and PE expression using the Accuri C6 flow cytometer with a blue laser $(488 \mathrm{~nm})$ and a suitable detector (FL1 path; 530/30 nm filter). A least $10 \mathrm{k}$ of gated events was attained from each cell population, and the analysis was conducted with the Accuri software.

\section{Animal studies with mice bearing LNCaP xenografts}

Animal studies were conducted using the protocol described by Yang et al. [16] with minor variations. For the purposes of the study, female nude mice aged 6-8 weeks were preserved in $12 \mathrm{~h}$ light $/ 24 \mathrm{~h}$ dark cycle. LNCaP cells were cultured in DMEM, and the xenografts were developed after the injection of the cells $\left(2 \times 10^{6}\right)$ in the fat pad of mammary glands. The tumours grew for 3 days (no treatment provision), and the volumes were monitored daily through recording two perpendicular tumour diameters with a calliper:

[tumour volume $[\mathrm{mm} 3]=($ length $[\mathrm{mm}]) \times(\text { width }[\mathrm{mm}])^{2} \times 0.52$

The mice bearing LNCaP xenografts were allocated into groups $(n=6)$ in order to receive the required treatment: (1) blank control, (2) CRN ethanolic solution, (3) 
Table 2 Particle size and zeta potential of NLC formulations $(n=3)$

\begin{tabular}{llll}
\hline & Months & Particle size $(\mathbf{n m})$ & Zeta potential $(\mathbf{m V})$ \\
\hline Blank NLC & 1 & $113.7 \pm 1.2$ & $-44.1 \pm 1.4$ \\
& 3 & $115.0 \pm 0.8$ & $-44.1 \pm 0.3$ \\
& 6 & $118.3 \pm 1.3$ & $-42.9 \pm 0.9$ \\
CRN-NLC & 1 & $146.5 \pm 1.1$ & $-42.8 \pm 0.6$ \\
& 3 & $147.7 \pm 1.7$ & $-41.1 \pm 1.0$ \\
& 6 & $149.6 \pm 2.4$ & $-40.6 \pm 0.7$ \\
\hline
\end{tabular}

BL-NLC and (4) CRN-NLC. Each sample was administered through intravenous injection via mice tail with CRN treatment of $20 \mathrm{mg} / \mathrm{kg}$. The injections were repeated twice per week at $200 \mu \mathrm{l}$ per injection for 30 days. The tumour size and the mice weight were measured and recorded twice a week.

\section{Statistical analysis}

The experimental findings are presented as means and standard deviation of the mean $(n=3)$. $T$-test analysis was introduced to investigate the differences between blank CRN and CRN-NLC dispersions while the effects were considered statistically significant only when the probability factor $p<0.05$.

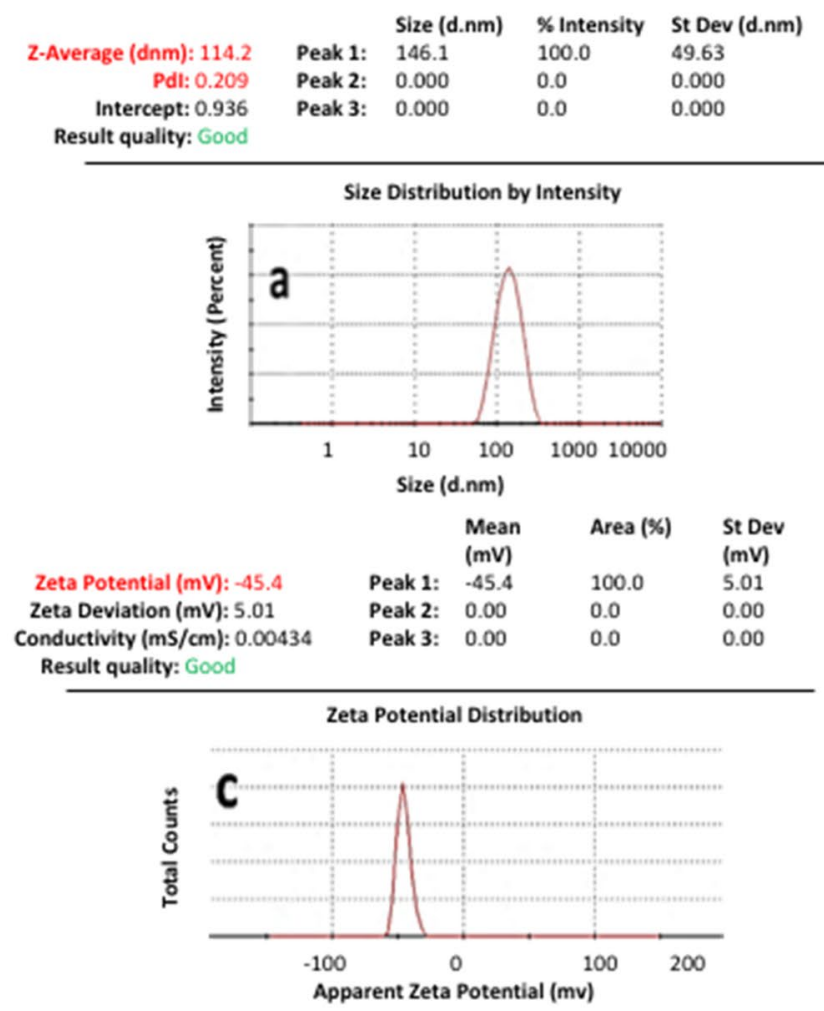

\section{Results and discussion}

\section{NLC particle size and ל-potential}

The obtained BL-NLC and CRN-NLCs were successfully prepared using HPH by adjusting the homogenization temperature and the applied pressure. All materials used for the NLCs including the lipids, surfactant and oily phase were generally recognised as safe (GRAS). The freshly made BLNLC and CRN-NLC are characterised in terms of both particle size distribution and $\zeta$-potential, as shown in Table 2 but also evaluated after 6 months storage stability at $4{ }^{\circ} \mathrm{C}$. Figure 1 shows that the particle size of blank and CRNloaded NLCs varied from 110 to $150 \mathrm{~nm}$. The drug encapsulation led to a slight particle increase of about $35 \mathrm{~nm}$. The produced nano dispersions presented a monomodal particle size distribution for blank CRN-loaded formulations.

HPH was optimized (data not shown) to produce NLCs smaller than $<150 \mathrm{~nm}$ in order to assure their acceptability for cancer treatment as size plays a critical role in cellular uptake monomodal particle size distribution, while particle decrease results in improved bioavailability [18].

Furthermore, the observed polydispersity indexes for all NLCs were around 0.2 indicating uniform size populations. The measured $\zeta$-potential showed negative surface charge

\begin{tabular}{rllll} 
& & Size (d.nm) & \% Intensity & St Dev (d.nm) \\
Z-Average (dnm): 145.7 & Peak 1: & 178.8 & 100.0 & 83.82 \\
Pdl: 0.170 & Peak 2: & 0.000 & 0.0 & 0.000 \\
Intercept: 0.952 & Peak 3: & 0.000 & 0.0 & 0.000 \\
Result quality: Good & & & & \\
\hline
\end{tabular}
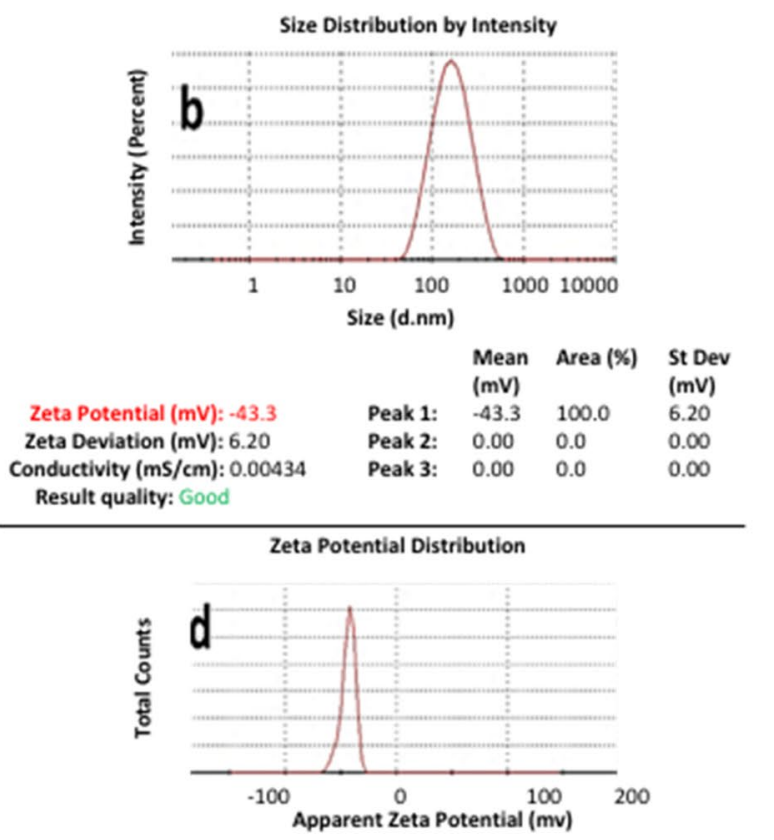

Fig. 1 Particle size distribution and $\zeta$-potential of A, C BL-NLC, B, D CRN-NLC respectively 
Fig. 2 In vitro $C R N$ release from NLCs

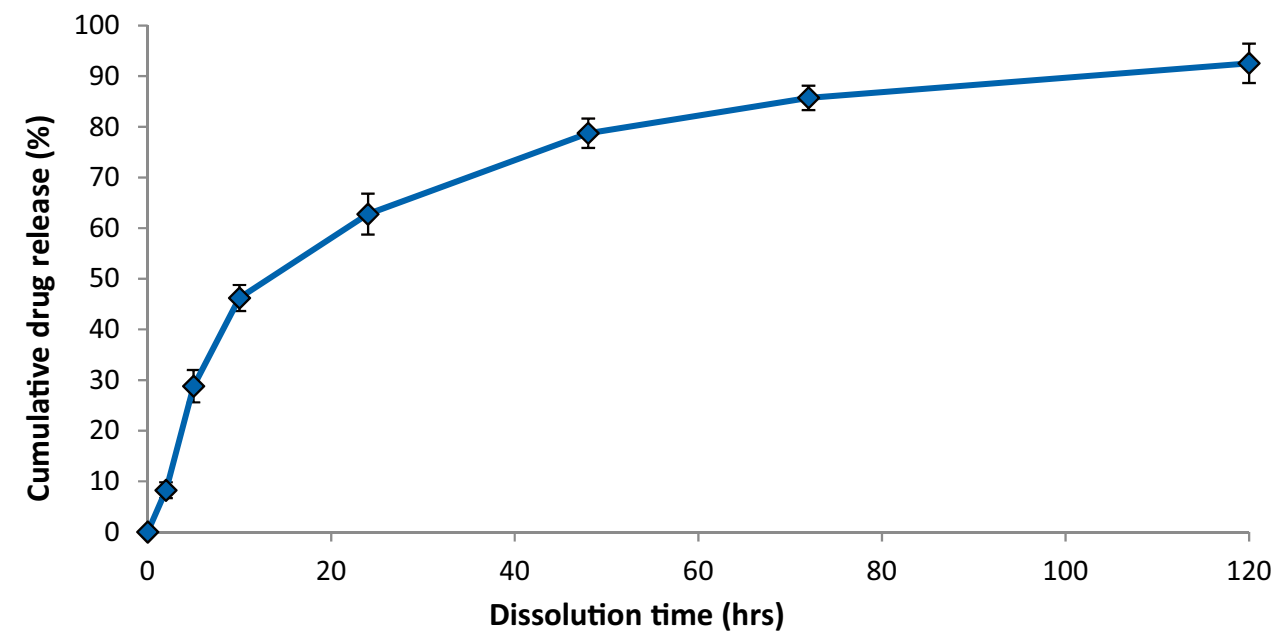

and varied from 40 to $45 \mathrm{mV}$. Those values were considered indicative of NLC long-term stability as colloidal nanoparticles are considered stable when $\zeta$-values are greater than $30 \mathrm{mVas}$ a result of the electric repulsion [19]. For the CRN-NLCs $(-42.8 \pm 0.6)$ a small $\zeta$-potential decrease was observed compared to BL-NLC $(-44.1 \pm 1.4)$ after 6 months storage stability. The reduction can be explained through the drug partial absorption on the NLC surface resulting in masking the surfactant negative charge [19].

\section{Evaluation of the DL and EE}

Further investigation of the CRN-NLC dispersions showed good DL and EE with $9.3 \%$ and $92.9 \%$, respectively. Moreover, the high EE of the CRN-loaded nanoparticles denoted the efficiency of HPH for the encapsulation of lipophilic compounds with negligible drug losses during homogenization. The achieved DL and EE of CRC-NLCs were related to the lipophilic nature of the drug and the less ordered NLC crystal lattice which favours the incorporation of drugs in the lipidic matrix [20]. The DL and EE findings were in good agreement with previous studies that demonstrated similar outcomes [21].

\section{Drug release studies}

The practicality of employing NLC to distribute CRN was one of the main topics explored in this study. As illustrated in Fig. 2, the potential of NLC to deliver CRN is investigated by evaluating the drug release. The release test lasted $120 \mathrm{~h}$ at a constant temperature of $37^{\circ} \mathrm{C}$. Because of the hydrophobic nature of CRN, the release tests were carried out in $50 \% \mathrm{v} / \mathrm{v}$ ethanol solutions, with CRN solubility of $0.693 \pm 0.13 \mathrm{mg} / \mathrm{ml}$, as proposed by Kakkar et al. [22].

Two distinct trends appear to characterise the CRN release pattern. Over the first $10 \mathrm{~h}$, there was a burst effect, followed by a steady drug release from NLCs for the remainder of the monitoring period. After $48 \mathrm{~h}$, the cumulative
Fig. 3 MTT assay used to test the antiproliferative effects of pure $\mathrm{CRN}$ on $\mathrm{LNCaP}$ cells for 24 h. $(n=3)$

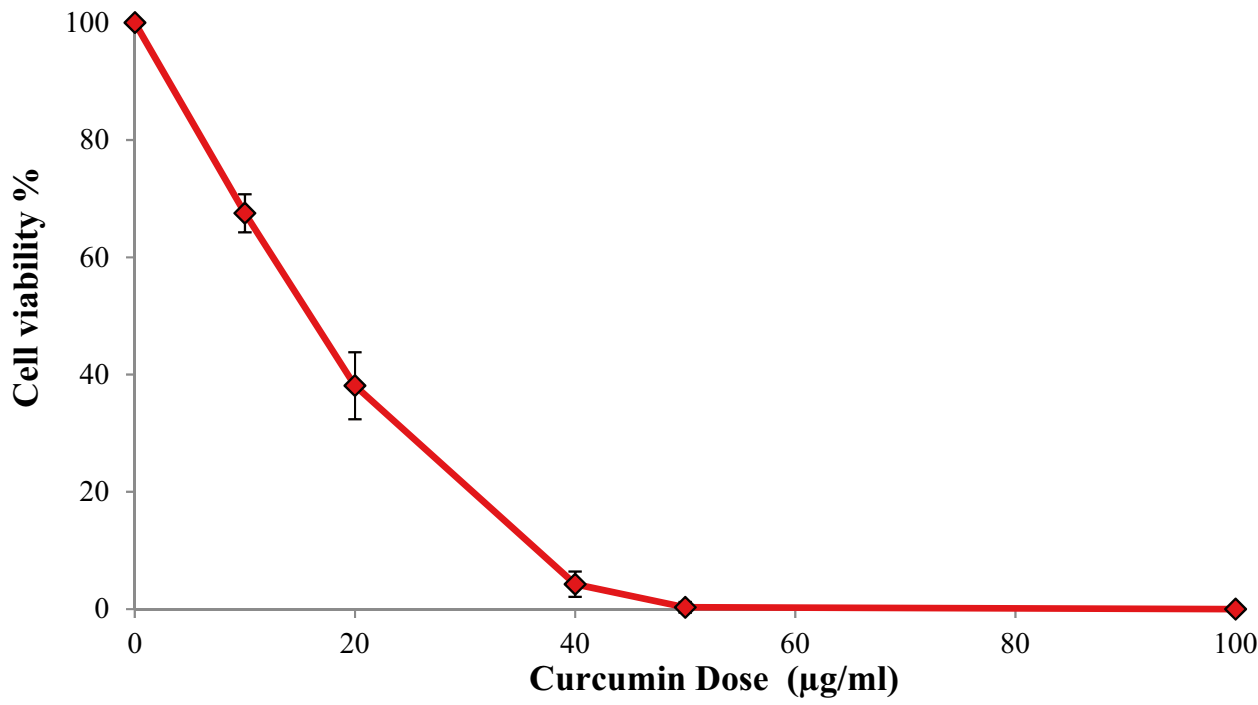


Fig. 4 Cell viability of blank NLCs in LNCaP cancer cells. $(n=3)$

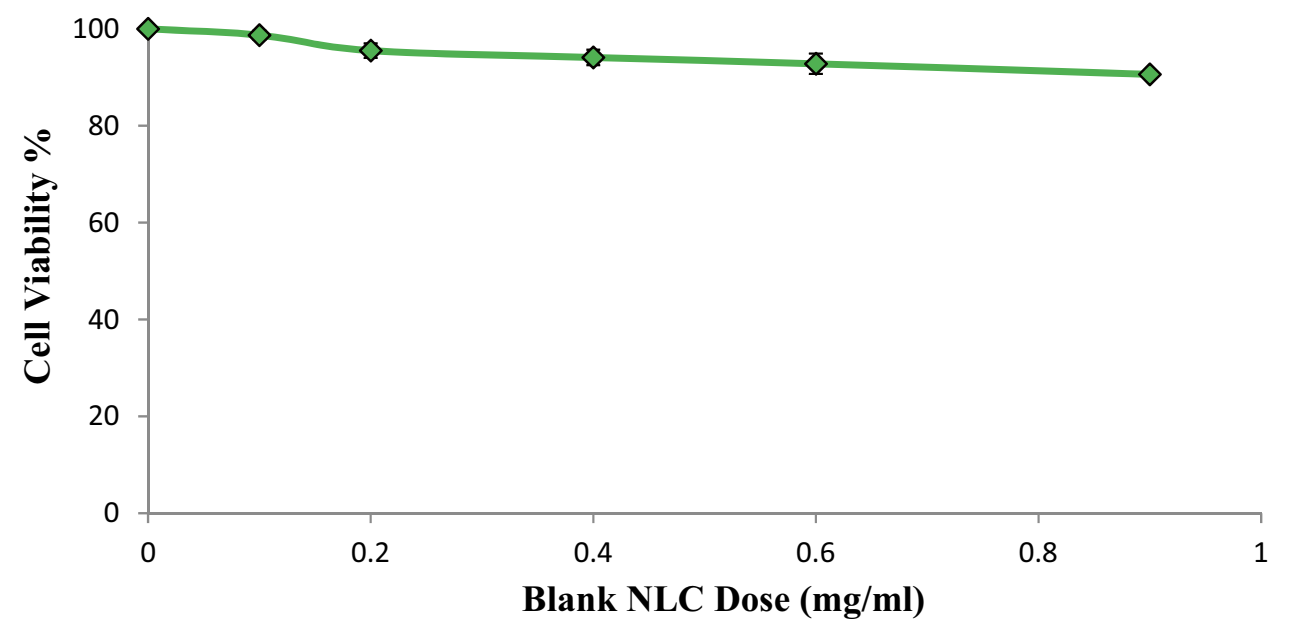

release rate was $78.8 \%$ where over the next $72 \mathrm{~h}$, this figure increased to $92.6 \%$. The discovery is in line with other researchers' results on CRN release from lipid nanoparticles [20]. Despite the fact that the components utilised to make CRN-loaded lipid nanoparticles differed from those used in this study, the obtained results can be justified: The absorbed CRN on the surface of NLC causes the burst release, while the time necessary for the drug to diffuse into the dissolution medium from the NLC causes the sustained release [23].

\section{CRN antiproliferative effect}

The tumour killing activity of CRN-loaded NLC formulations was assessed using the MTT test against LNCaP prostate cancer cells to measure their cytotoxicity. The antiproliferative activity of CRN-loaded NLC formulations was tested to see if CRN's efficacy was maintained after encapsulation in a lipid matrix. The antiproliferative activity of pure CRN on the LNCaP cell lines was investigated initially, and the CRN-NLC drug delivery system was compared.

As illustrated in Fig. 3 after 24 h of incubation, bulk CRN showed excellent antiproliferative efficacy. CRN presents some of the most sought properties of a cancer therapeutic drug, where preferential killing or therapeutic selectivity is one of them. Hence, CRN can be used to selectively target cancer cells while causing minimal harm to healthy cells [24]. The in vitro antiproliferative effect of CRN was substantial, indicating CRN's efficacy against LNCaP cancer cells.

\section{NLC's antiproliferative effect}

The cytotoxicity of blank NLCs is a crucial consideration when using it as a drug career, while lipid nanoparticles with low cytotoxicity are required for cancer applications. To assess the effect of blank NLCs, their cytotoxicity was tested on LNCaP prostate cancer cells.

Blank NLCs had no influence on the cytotoxicity of the LNCaP cancer cells as shown in Fig. 4. After 24 h of incubation at a high NLC concentration $(0.9 \mathrm{mg} / \mathrm{ml})$, cell viability was $91.0 \%$ which is deemed insignificant [25].

The MTT assay was used to assess the antiproliferative impact of CRN-NLC. As demonstrated in Fig. 5, increases in CRN concentration had an influence on the viability of

Fig. 5 Cell viability of CRN-NLCs after 24 and $48 \mathrm{~h}$ ${ }^{\#} p=0.0323,{ }^{*} p<0.0001$, CRN-NLC (24 h) vs. BL-NLC and ${ }^{\# \#} p=0.0003,{ }^{*} p<0.0001$, CRN-NLC (48 h) vs. BL-NLC $(n=3)$

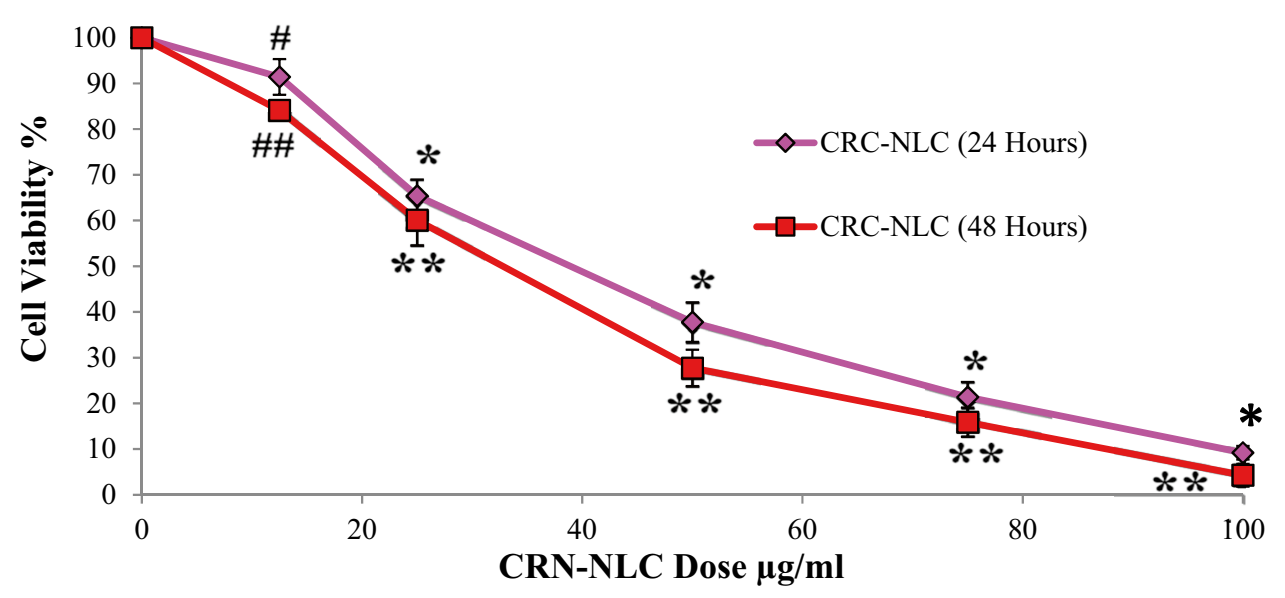


LNCaP cells, which was reduced to $91.5 \%$ at the lowest dose of $12.5 \mathrm{~g} / \mathrm{ml} \mathrm{CRN}$ concentration.

The antiproliferative action of CRN-NLC was even more pronounced at higher CRN concentrations of $50 \mathrm{~g} / \mathrm{ml}$ and $75 \mathrm{~g} / \mathrm{ml}$, with cell viability reduced to $37.8 \%$ and $21.4 \%$, respectively. The cell viability was further reduced to $9.2 \%$ at a dose of $100 \mathrm{~g} / \mathrm{ml}$, which is regarded very significant when compared to the blank NLC nanoparticles $(p<0.0001)$.

These results clearly show that CRN-NLCs have a dosedependent antiproliferative effect on the LNCaP cells. However, as a continuous release pattern of CRN was observed in CRN-NLC release investigations, a further 48-h study on $\mathrm{LNCaP}$ cells was also undertaken to further investigate this finding.

The antiproliferative impact was considerably more pronounced after $48 \mathrm{~h}$ of CRN incubation, as expected. Cell viability was nearly $0 \%$ after extending the incubation period at $100 \mathrm{~g} / \mathrm{ml}$ CRN concentration. Our experimental findings were similar to those reported by Fang in a previous study [21].

This CRN-NLC's time-dependent cytotoxic effect is a clear evidence of CRN's sustained release, as well as
Fig. 6 Cellular uptake of drugloaded nanoparticle where the green colour shows internalization of CRC-NLCs. The nucleus was stained with the blue colour of (DAPI)

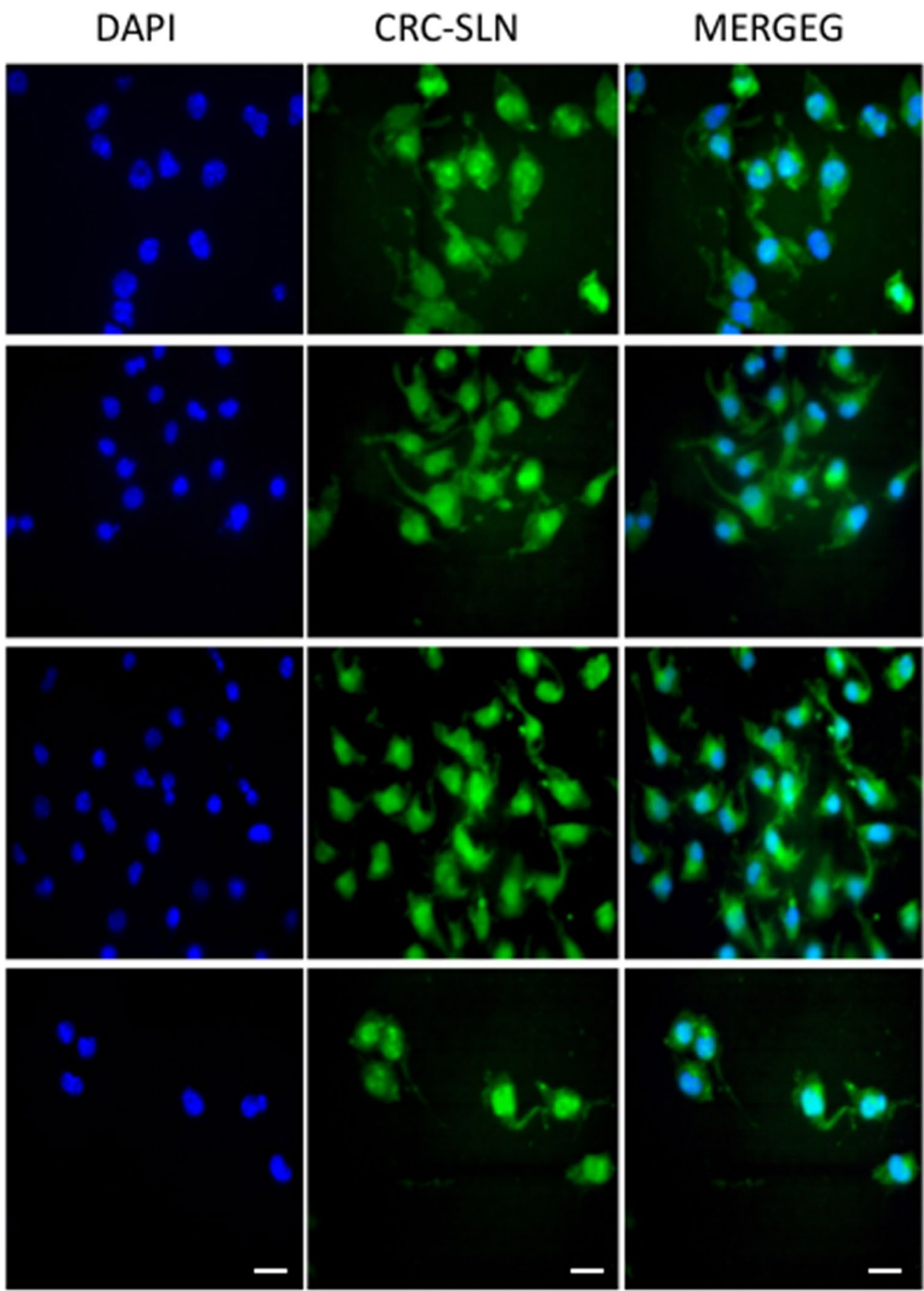


CRN-extended NLC's inhibitory effect. Because blank NLCs presented no effect on the cytotoxicity of LNCaP cells, it was concluded that the CRN molecules were primarily the cause of the reduced cell cytotoxicity.

\section{Investigation of cellular uptake}

CRN's inherent fluorescence, which can be used directly to quantify its cellular uptake, is one of its advantages. The cellular uptake of CRN-NLCs was studied using fluorescence microscopy; laser intensity, offset, sensitivity, and gain constant were harmonised during cell imaging to better understand the internalisation of the CRN-NLC inside the cell.

NLCs are known to enter cells via endocytotic routes, according to Mohanty and Sahoo (2010). Their internalisation was confirmed by incubating $10-30 \mu \mathrm{M}$ of native CRC and equivalent amounts in nanoparticulate formulations in PANC-1 cells for $24 \mathrm{~h}$ and qualitative cellular absorption experiments were carried out after incubation [26].

Prior to the experiment, the nucleus of the cell was labelled with DAPI, a DNA specific fluorescent probe [27], and the images were acquired after fixation. Figure 6 shows overlay pictures that clearly demonstrate green (CRN-NLC) and blue (nucleus) patches, showing CRN-NLC internalisation within the cytoplasm of the nucleus.

\section{Flow cytometry of NLCs}

CRN accumulation on LNCaP cells after $24 \mathrm{~h}$ incubation of CRN-NLC is seen in flow cytometric histograms in Fig. 7. For each cell, the signal intensity was measured quantitatively, and the expression of a high proportion of cellular uptake is linked to high fluorescence intensity.

As shown in Fig. 7, CRN-NLC presents signal intensity of $96.2 \%$, according to the histogram. Blank NLCs were also examined for any autofluorescence effects and interference with the fluorescent intensity produced by CRN-NLC. Figure 7 shows that no fluorescence intensity was detected, while the results from the quantitative cellular uptake of CRN-NLC matched the images captured by fluorescence microscopy.

\section{In vitro apoptosis}

Apoptosis is a physiologically regulated cell death that happens during the growth of cells, and it is distinguished from necrosis. PS is exposed to the exterior cellular surroundings when phosphadylcholine (PS; located on the cytoplasmic side of a normal cell bilayer) is translocated from the inner to the outer leaflet of the plasma membrane during apoptosis [28].

PE Annexin V and 7AAD were used to stain both untreated and treated cells. Because Annexin V has a high affinity for PS, it can detect apoptosis at an early stage (Annexin $\mathrm{V}$ positive, 7AAD negative). The combination of 7AAD with PE Annexin V allows for the detection of early apoptotic cells. Dead and impaired cells are permeable to $7 \mathrm{AAD}$, but live cells with intact membranes exclude it.

Flow cytometry is used to identify and quantify the induction of apoptosis by CRN following the treatment on cells, as shown in Fig. 8. Pure CRN (15 g/ml) demonstrated $12 \%$ early apoptotic cells and $24 \%$ late apoptotic/ early necrotic cells, while cells are treated with CRNNLC nanoparticles. Cells treated with CRN-NLC $(25 \mu \mathrm{g} /$ $\mathrm{ml} \mathrm{CRN}$ ), revealed $17.6 \%$ and $18.2 \%$ early apoptotic (Annexin $\mathrm{V}+7 \mathrm{AAD}$ ) and late apoptotic/early necrotic (Annexin $\mathrm{V}+7 \mathrm{AAD}+$ ) populations, respectively. This showed that, like pure CRN, CRN-NLCs trigger apoptotic pathways. A considerable upsurge in apoptotic cells was seen at higher concentrations of $50 \mathrm{~g} / \mathrm{ml}$ and $100 \mathrm{~g} / \mathrm{ml}$. In cells treated with CRN-NLC at $50 \mathrm{~g} / \mathrm{ml}$ CRN dosage, the percentages of early apoptotic (Annexin $\mathrm{V}+7 \mathrm{AAD})$ and late apoptotic/early necrotic (PE Annexin V+7AAD +) populations were $19.8 \%$ and $42.7 \%$, respectively. Experimentation with untreated and BL-NLC controls revealed
Fig. 7 Cellular uptake of A BLNLCs and $B$ CRN-NLC by flow cytometric analysis
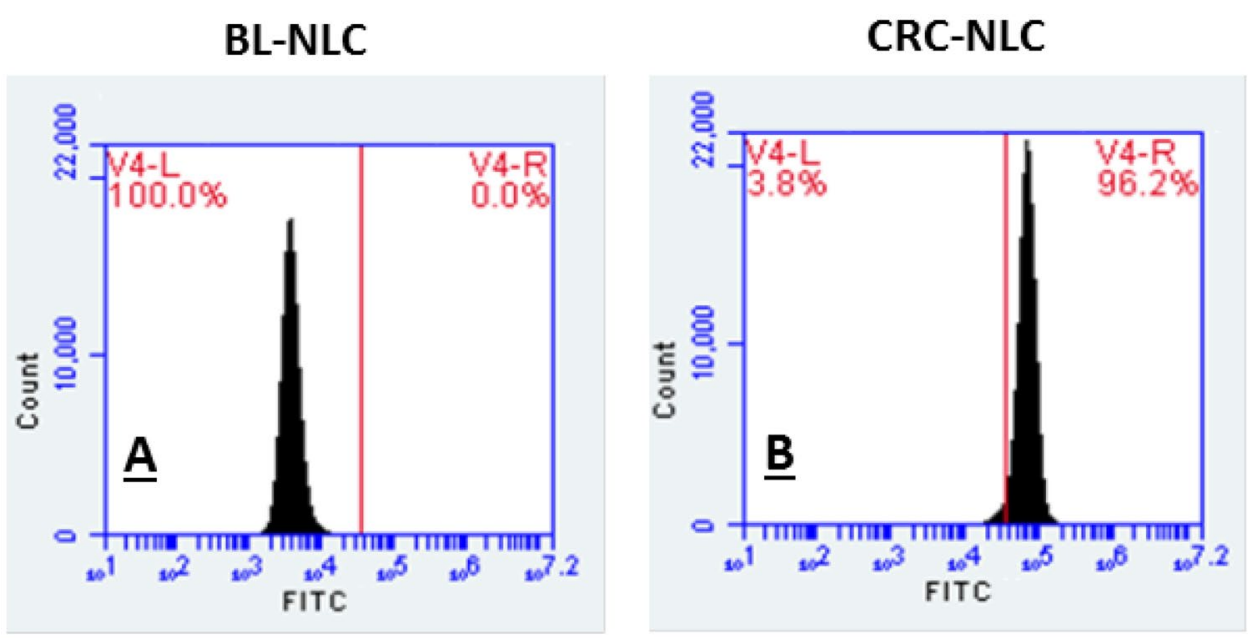

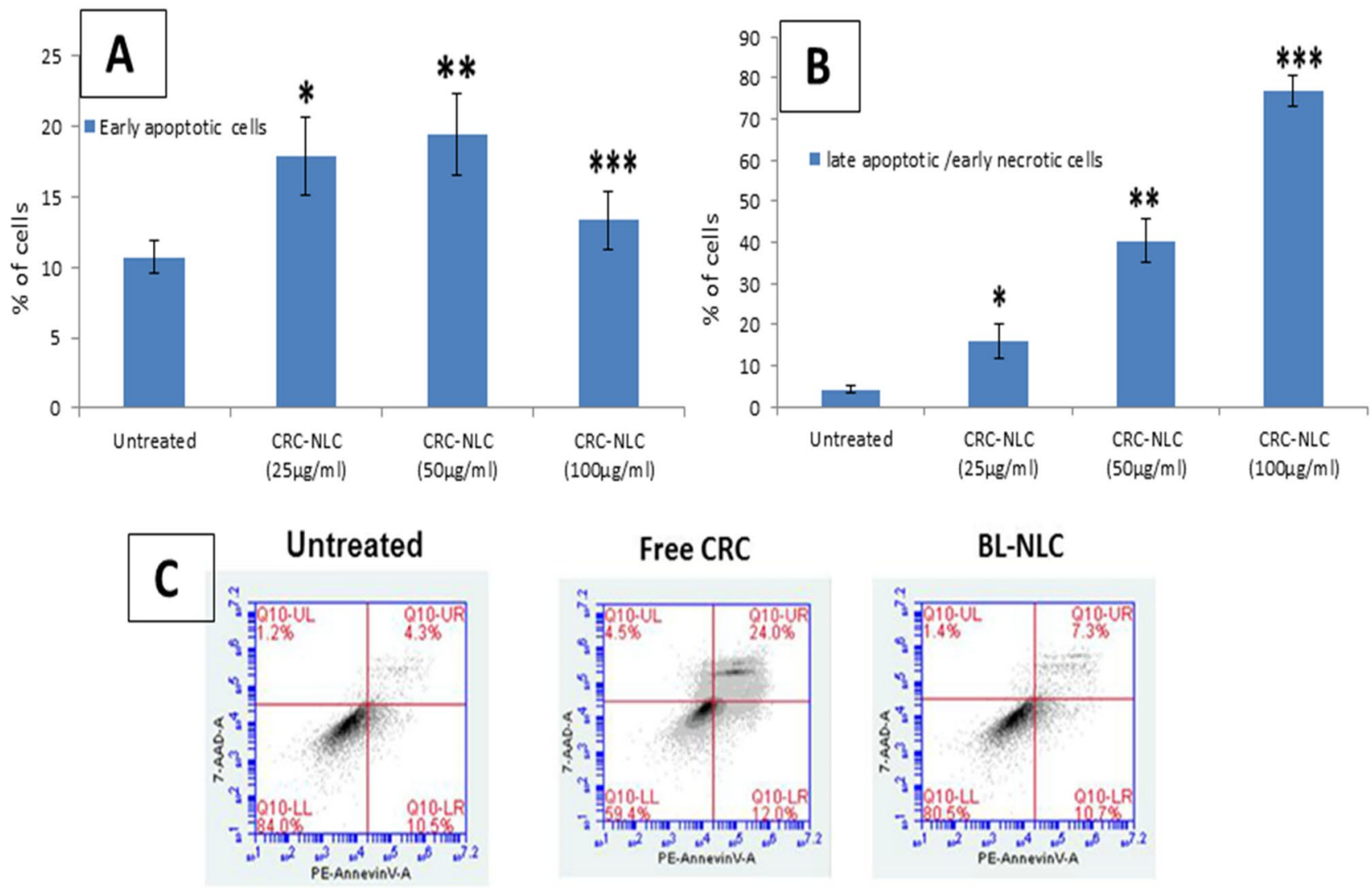

Free CRC

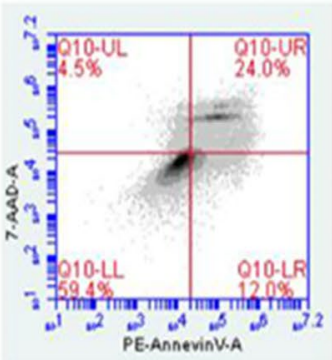

CRC-NLC $(50 \mu \mathrm{g} / \mathrm{ml})$

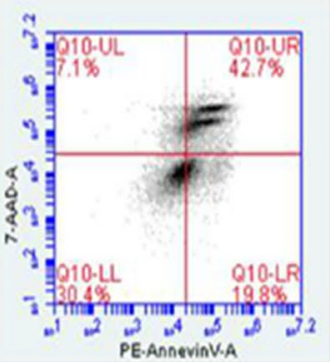

BL-NLC

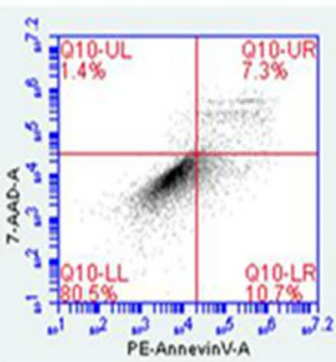

CRC-SLN $(100 \mu \mathrm{g} / \mathrm{ml})$

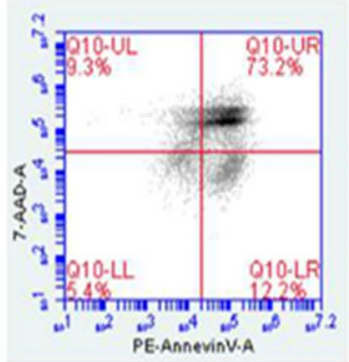

Fig. 8 Quantitative apoptotic analysis in $\mathrm{LNCaP}$ cells treated with BL-NLC, pure CRN and CRN-NLC. A Treatment with a concentration of 25,50 or $100 \mathrm{~g} / \mathrm{ml}$ of CRN-NLC dosage for $24 \mathrm{~h}$ had a dosedependent effect on early apoptosis, as evaluated by flow cytometry. B Treatment with concentrations of 25,50 and $100 \mathrm{~g} / \mathrm{ml}$ of CRNNLC dosages for $24 \mathrm{~h}$ had a dose-dependent influence on late apoptosis, as measured by flow cytometry (bar charts). (*) $p<0.05$, con-

no apoptotic impact, implying that the apoptosis generated by the CRN-NLCs was due to encapsulated CRN.

\section{In vivo anticancer activity of CRN and CRN-NLC on LNCaP tumours}

The blank NLC, pure CRN as well as CRN-NLC, were injected in mice xenografts of LNCaP tumours at doses trol vs. CRN-NLC $(25 \mu \mathrm{g} / \mathrm{ml}),(* *) p<0.05$, control vs. CRN-NLC $(50 \mu \mathrm{g} / \mathrm{ml}),(* * *) p<0.05$, control vs. CRN-NLC $(100 \mu \mathrm{g} / \mathrm{ml})$ and C PE Annexin V vs. 7-AAD dot plots are used to represent dosedependent effects. Top right: late apoptotic cells/early necrotic cells; Top left: necrotic cells; bottom right: early apoptotic cells; bottom left: live cells; and $(n=3)$

of $20 \mathrm{mg} / \mathrm{kg}$ to investigate their in vivo anticancer activity. The prostate cancer cells were inoculated with a cell density of $1 \times 10^{6}$ in mice, and the cells were allowed to develop for a total of 6 days before starting treatments with various formulations.

Unpaired $t$-test was utilised to assess statistically significant differences between each set of NLCs, revealing the anticancer efficacy differences between each formulation. 
The anticancer activity of $\mathrm{CRN}$ is shown in Fig. 9 in comparison to the control and blank NLCs, with the data expressed in terms of mean tumour tissue weight in each group.

When CRN was administrated to mice with LNCaP tumours, the tumour size was reduced by $19 \%$ when compared to the control treatment. Furthermore, an unpaired $t$-test between these two groups revealed a significant difference, with $p=0.020$. When mice with tumours were given CRN-NLCs, the anticancer impact was significantly stronger.

When compared to the control and the BL-NLC group, a tumour size reduction of $52 \%$ and $50 \%$ was seen after 4 weeks of therapy with CRN-NLC nanoparticles. The therapeutic efficacy of the CRN-NLCs was substantially higher when compared to the control and blank NLC groups, according to an unpaired t-test $(p<0.0001)$. The comparison of tumour weight between the bulk CRN and that of CRN-NLC, demonstrated that animal weight was reduced by $40 \%$ for the latter. This evidently demonstrates the benefit of the CRN usage as a drug delivery system for cancer treatment.

As the animal trials of pure CRN and CRN-NLC nanoparticles revealed anticancer action, they were measured in terms of tumour volume. As illustrated in Fig. 9, when compared to control and blank NLC-administrated mice, treatment with bulk CRN and CRN-NLCs resulted in considerable tumour regression of LNCaP xenografts. Figure 10 shows the findings of tumour volume changes as a function of time with CRN-loaded NLC. After 4 weeks of therapy, the average tumour variations in LNCaP tumours were $1412.0 \mathrm{~mm}^{3}$ (control), $1375.2 \mathrm{~mm}^{3}$ (blank NLCs), $1155.1 \mathrm{~mm}^{3}$ (pure CRN) and $778.4 \mathrm{~mm}^{3}$ (CRN-NLCs). When compared to control and BL-NLC, the NLC-CRN exhibited a substantial growth inhibitory activity $(p<0.0001)$. Furthermore, as compared to pure CRN $(p<0.0001)$, CRN-NLC demonstrated better anticancer activity. Another noteworthy finding was the tumour-suppressing properties of the BL-NLC nanoparticles. Figure 10 shows that, alike to control therapy $(p=0.1300)$, blank NLC did not demonstrate any substantial reduction in tumour suppression.

The weight of the mice was also monitored for 4 weeks during the dose administration, and no weight changes were seen in any of the animals that received the treatment. Figure $2 \mathrm{~S}$ (supplementary data) revealed that the nanoparticles were well tolerated by the mice, who showed no evidence of toxicity or considerable weight loss.

Despite the fact that CRN is known to be highly effective in commencing protection against cancer in animals exposed to a range of chemical carcinogens, CRN's bioavailability is known to be low [29]. CRN can also decrease cell proliferation and signal transduction activation in cancer cells that present either androgenic or non-androgenic activities. CRN has been reported to decrease both constitutive and inducible nuclear factor-B and so has high antioxidant and anti-inflammatory properties [30].

CRN encapsulation in NLC can help to alleviate some of the bioavailability issues associated with intravenous delivery of CRN, allowing for optimal anticancer activity when delivered at the tumour site. According to previous studies, drug encapsulation can lead to increased CRN plasma concentrations, which could be due to the nanoparticle's small size; this, in turn, facilitates the NLC circulation for prolonged time which may result in a higher anticancer efficacy [31, 32]. Similar experimental outcomes were found by Chen et al. (2012) where CRN and CRN-NLC administration successfully slowed tumour growth and prolonged mice survival but did not complete eliminate tumour growth [33].
Fig. 9 Comparison of tumour suppression on $\mathrm{LNCaP}$ prostate cancer of control, blank NLC, pure CRN, CRN-NLCs

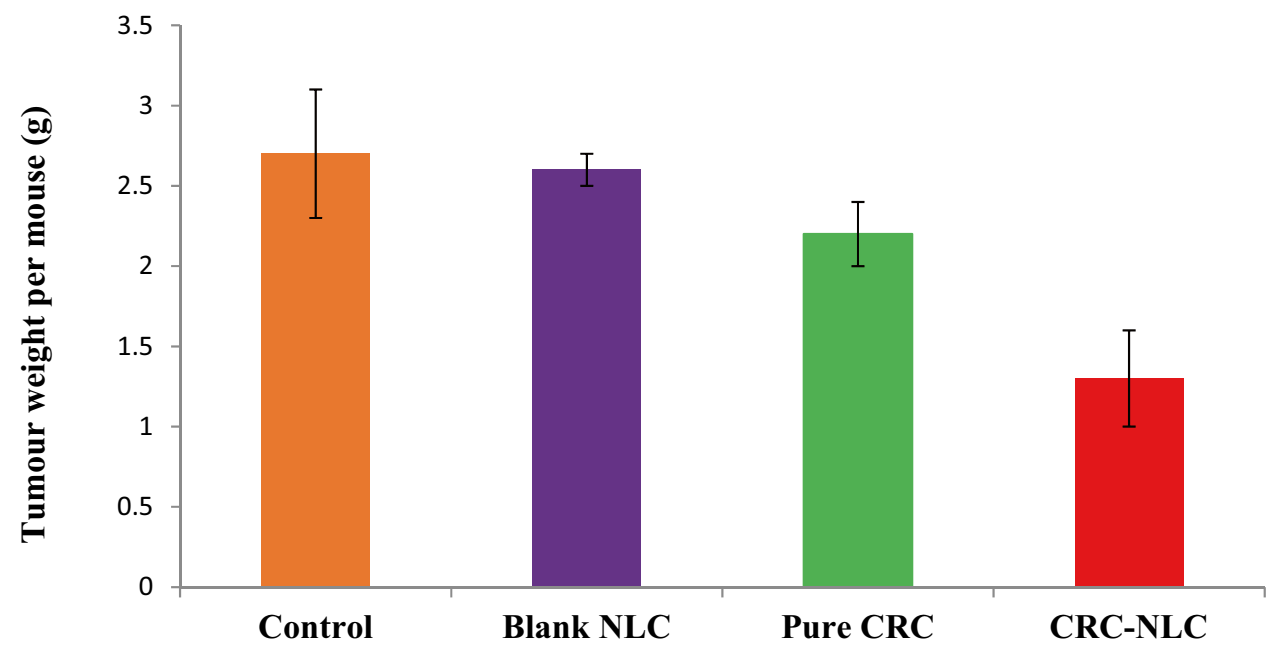


Fig. 10 Therapeutic impact of control, blank NLC, pure CRN and CRN-NLC on tumourbearing animals (top) and tumour growth in mice bearing LNCaP tumours after treatment with CRC-NLC

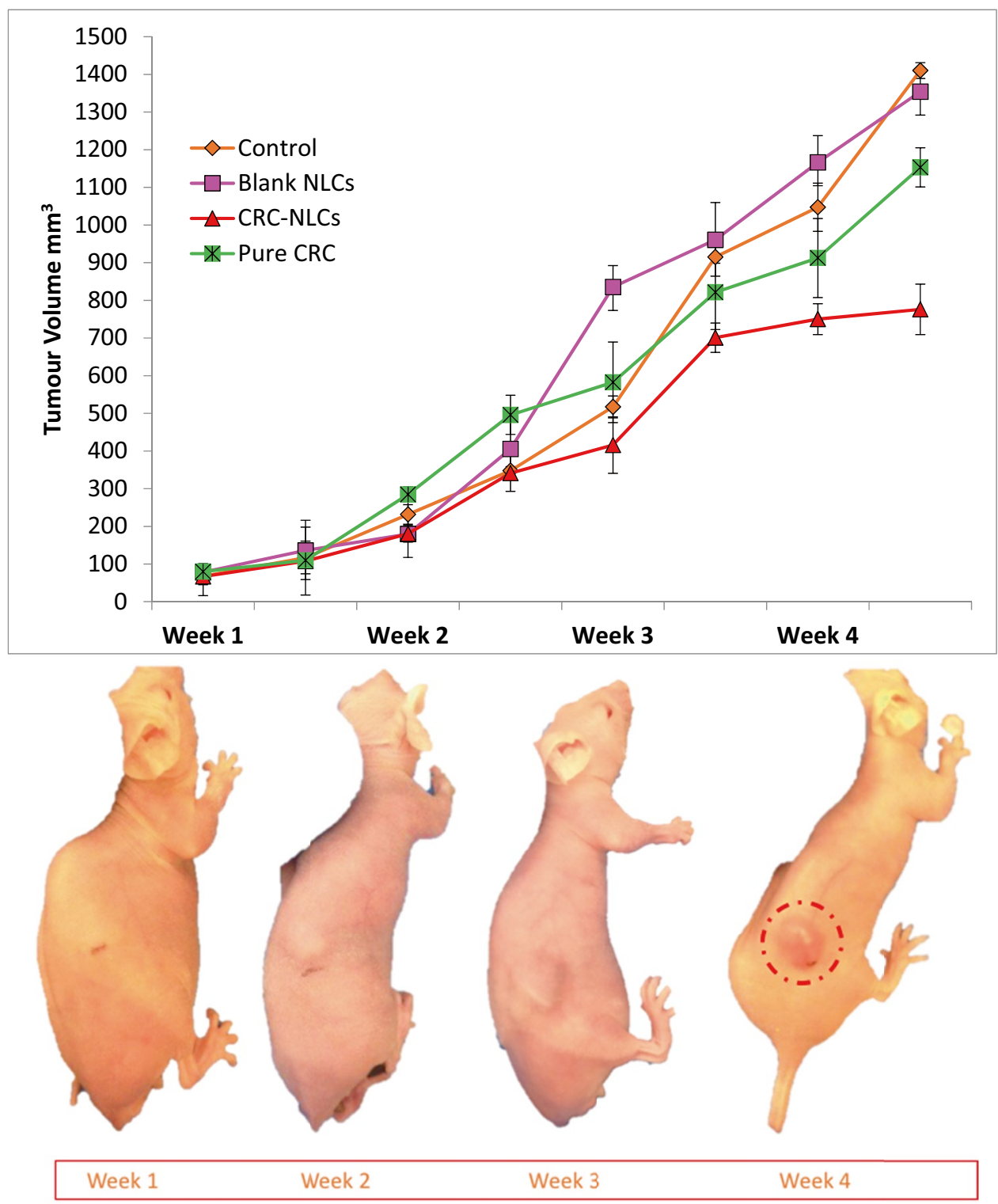

\section{Conclusions}

In the current work, CRN-NLC nanoparticles were effectively produced by employing high pressure homogenization with narrow particle size distribution, low $\zeta$-potential $(-40 \mathrm{mV})$ values, and long-term stability. CRN was encapsulated efficiently within SLNs, and in vitro release tests revealed prolonged release. Cytotoxicity experiments demonstrated considerable cell growth suppression after treatment with CRN-NLC, and cell viability reduced to $4.3 \%$ at a CRN dose of $100 \mu \mathrm{g} / \mathrm{ml}$. Flow cytometry analysis demonstrated CRN-NLC apoptosis, with $76.9 \%$ of cells on late apoptotic/early necrotic cells. In vivo investigations on $\mathrm{LNCaP}$ cancer xenografts demonstrated that CRN-NLC nanoparticles had a much higher anticancer efficacy than empty NLCs and pure CRN. CRN-NLC nanoparticles showed considerable tumour suppression, rendering it a suitable drug delivery system for the treatment of prostate cancer.

Supplementary information The online version contains supplementary material available at https://doi.org/10.1007/s13346-021-01095-1.

\section{Acknowledgements N/A}

Author contribution D. Douroumis and G. Getti (conceptualization, methodology, supervision, validation, writing, project administration), M. Akanda (investigation, validation formal analysis, writing — original draft).

Availability of data and materials N/A. 


\section{Declarations}

Ethical statement Ethical approval for conducting experiment on animals has been sought and obtained as necessary.

\section{Ethics approval and consent to participate N/A}

Consent for publication I, Prof Dennis Douroumis, corresponding author of this research article on behalf of all the authors (Dr Mushfiq Akanda, Dr Giulia Getti), hereby confirm that this article is original, does not infringe on any copyright, is not under consideration by any other journal and has not been previously published.

Conflict of interest The authors declare no competing interests.

Open Access This article is licensed under a Creative Commons Attribution 4.0 International License, which permits use, sharing, adaptation, distribution and reproduction in any medium or format, as long as you give appropriate credit to the original author(s) and the source, provide a link to the Creative Commons licence, and indicate if changes were made. The images or other third party material in this article are included in the article's Creative Commons licence, unless indicated otherwise in a credit line to the material. If material is not included in the article's Creative Commons licence and your intended use is not permitted by statutory regulation or exceeds the permitted use, you will need to obtain permission directly from the copyright holder. To view a copy of this licence, visit http://creativecommons.org/licenses/by/4.0/.

\section{References}

1. Ramalho MJ, Andrade S, Loureiro JA, do Carmo Pereira M. Nanotechnology to improve the Alzheimer's disease therapy with natural compounds. Drug Deliv Transl Res. 2020. https://doi. org/10.1007/s13346-019-00694-3.

2. Muller RH, Shegokar R, Keck CM. 20 years of lipid nanoparticles (SLN \& NLC): present state of development \& industrial applications. Curr Drug Discov Technol. 2011. https://doi.org/10.2174/ 157016311796799062.

3. Almeida AJ, Souto E. Solid lipid nanoparticles as a drug delivery system for peptides and proteins. Adv Drug Deliv Rev. 2007. https://doi.org/10.1016/j.addr.2007.04.007.

4. Alam T, Ansari MA, Baboota S, Ali J. Nanostructured lipid carriers of isradipine for effective management of hypertension and isoproterenol induced myocardial infarction. Drug Deliv Transl Res. 2021. https://doi.org/10.1007/s13346-021-00958-x.

5. Pineda-Hernández MT, Pérez-Urizar JT, Ganem-Rondero A. Thermo-reversible in situ forming implant with nanostructured lipid carriers (NLC) as a delivery system for the administration of estradiol valerate. Drug Deliv Transl Res. 2020. https://doi.org/ 10.1007/s13346-019-00704-4.

6. Mahmood A, Rapalli VK, Gorantla S, Waghule T, Singhvi G. Dermatokinetic assessment of luliconazole-loaded nanostructured lipid carriers (NLCs) for topical delivery: QbD-driven design, optimization, and in vitro and ex vivo evaluations. Drug Deliv Transl Res. 2021. https://doi.org/10.1007/s13346-021-00986-7.

7. Wiemann S, Keck CM. Are lipid nanoparticles really superior? A holistic proof of concept study. Drug Deliv Transl Res. 2021. https://doi.org/10.1007/s13346-021-01021-5.

8. Nnamani PO, et al. Formulation and evaluation of transdermal nanogel for delivery of artemether. Drug Deliv Transl Res. 2021. https://doi.org/10.1007/s13346-021-00951-4.
9. Gryczke A, Schminke S, Maniruzzaman M, Beck J, Douroumis D. Development and evaluation of orally disintegrating tablets (ODTs) containing Ibuprofen granules prepared by hot melt extrusion. Colloids Surf B Biointerfaces. 2011;86:275-284. https://doi. org/10.1016/j.colsurfb.2011.04.007.

10. Nguyen CN, Nguyen TTT, Nguyen HT, Tran TH. Nanostructured lipid carriers to enhance transdermal delivery and efficacy of diclofenac. Drug Deliv Transl Res. 2017. https://doi.org/10. 1007/s13346-017-0415-2.

11. Viegas JSR, et al. Nanostructured lipid carrier co-delivering tacrolimus and TNF- $\alpha$ siRNA as an innovate approach to psoriasis. Drug Deliv Transl Res. 2020. https://doi.org/10.1007/ s13346-020-00723-6.

12. Meng F, et al. A novel LDL-mimic nanocarrier for the targeted delivery of curcumin into the brain to treat Alzheimer's disease. Colloids Surfaces B Biointerfaces. 2015. https://doi.org/ 10.1016/j.colsurfb.2015.06.025.

13. Gurumukhi VC, Bari SB. Quality by design (QbD)-based fabrication of atazanavir-loaded nanostructured lipid carriers for lymph targeting: bioavailability enhancement using chylomicron flow block model and toxicity studies. Drug Deliv Transl Res. 2021. https://doi.org/10.1007/s13346-021-01014-4.

14. Rawal S, Patel B, Patel MM. Fabrication, optimisation and in vitro evaluation of docetaxel and curcumin Co-loaded nanostructured lipid carriers for improved antitumor activity against non-small cell lung carcinoma. J Microencapsul. 2020. https:// doi.org/10.1080/02652048.2020.1823498.

15. Mathur P, Sharma S, Rawal S, Patel B, Patel MM. Fabrication, optimization, and in vitro evaluation of docetaxel-loaded nanostructured lipid carriers for improved anticancer activity. J Liposome Res. 2020. https://doi.org/10.1080/08982104.2019. 1614055.

16. Yang L, et al. The effect of curcumin on proliferation and apoptosis in LNCaP prostate cancer cells. Chinese J Clin Oncol. 2006. https://doi.org/10.1007/s11805-006-0072-6.

17. Yang R, Zheng Y, Wang Q, Zhao L. Curcumin-loaded chitosanbovine serum albumin nanoparticles potentially enhanced A $\beta 42$ phagocytosis and modulated macrophage polarization in Alzheimer's disease. Nanoscale Res Lets. 2018;13:330. https://doi. org/10.1186/s11671-018-2759-z.

18. Verma DD, Verma S, Blume G, Fahr A. Particle size of liposomes influences dermal delivery of substances into skin. Int J Pharm. 2003;258(1):141-51. https://doi.org/10.1016/s0378-5173(03)00183-2.

19. Puglia C, et al. Curcumin loaded NLC induces histone hypoacetylation in the CNS after intraperitoneal administration in mice. Eur J Pharm Biopharm. 2012. https://doi.org/10.1016/j. ejpb.2012.03.015.

20. Nayak AP, Tiyaboonchai W, Patankar S, Madhusudhan B, Souto EB. Curcuminoids-loaded lipid nanoparticles: novel approach towards malaria treatment. Colloids Surfaces B Biointerfaces. 2010. https://doi.org/10.1016/j.colsurfb.2010.07.020.

21. Fang $M$, et al. In vitro characterization and in vivo evaluation of nanostructured lipid curcumin carriers for intragastric administration. Int J Nanomedicine. 2012. https://doi.org/10.2147/IJN. S36257.

22. Kakkar V, Singh S, Singla D, Kaur IP. Exploring solid lipid nanoparticles to enhance the oral bioavailability of curcumin. Mol Nutr Food Res. 2011. https://doi.org/10.1002/mnfr.201000310.

23. Castelli F, Puglia C, Sarpietro MG, Rizza L, Bonina F. Characterization of indomethacin-loaded lipid nanoparticles by differential scanning calorimetry. Int J Pharm. 2005. https://doi.org/10.1016/j. ijpharm.2005.08.011.

24. Liu J, Chen S, Lv L, Song L, Guo S, Huang S. Recent progress in studying curcumin and its nano-preparations for cancer therapy. Curr Pharm Des. 2013. https://doi.org/10.2174/1381612811319110003. 
25. Mulik RS, Mönkkönen J, Juvonen RO, Mahadik KR, Paradkar AR. Transferrin mediated solid lipid nanoparticles containing curcumin: enhanced in vitro anticancer activity by induction of apoptosis. Int J Pharm. 2010. https://doi.org/10.1016/j.ijpharm. 2010.07.021.

26. Mohanty C, Sahoo SK. The in vitro stability and in vivo pharmacokinetics of curcumin prepared as an aqueous nanoparticulate formulation. Biomaterials. 2010;31(25):6597-611. https://doi.org/ 10.1016/j.biomaterials.2010.04.062.

27. Suzuki T, Fujikura K, Higashiyama T, Takata. DNA staining for fluorescence and laser confocal microscopy. J Histochem Cytochem Off J Histochem Soc. 1997;45(1):49-53. https://doi.org/10. 1177/002215549704500107.

28. Speth PAJ, van Hoesel QGCM, Haanen C. Clinical pharmacokinetics of doxorubicin. Clin Pharmacokinet. 1988. https://doi.org/ 10.2165/00003088-198815010-00002.

29. Huang MT, Smart RC, Wong CQ, Conney AH. Inhibitory effect of curcumin, chlorogenic acid, caffeic acid, and ferulic acid on tumor promotion in mouse skin by 12-O-tetradecanoylphorbol13-acetate. Cancer Res. 1988.

30. Hour TC, Chen J, Huang CY, Guan JY, Lu SH, Pu YS. Curcumin enhances cytotoxicity of chemotherapeutic agents in prostate cancer cells by inducing $\mathrm{p} 21 \mathrm{WAF} 1 / \mathrm{CIP} 1$ and C/EBP $\beta$ expressions and suppressing NF- $\mathrm{\kappa B}$ activation. Prostate. 2002. https:// doi.org/10.1002/pros.10089.

31. Madane RG, Mahajan HS. Curcumin-loaded nanostructured lipid carriers (NLCs) for nasal administration: design, characterization, and in vivo study. Drug Deliv. 2016. https://doi.org/10.3109/ 10717544.2014.975382.

32. Duan J, et al. Synthesis and in vitro/in vivo anti-cancer evaluation of curcumin-loaded chitosan/poly(butyl cyanoacrylate) nanoparticles. Int J Pharm. 2010. https://doi.org/10.1016/j.ijpharm.2010. 08.033 .

33. Chen Y, Wu Q, Zhang Z, Yuan L, Liu X, Zhou L. Preparation of curcumin-loaded liposomes and evaluation of their skin permeation and pharmacodynamics. Molecules. 2012. https://doi.org/10. 3390/molecules 17055972 .

Publisher's Note Springer Nature remains neutral with regard to jurisdictional claims in published maps and institutional affiliations. 